\title{
Efficacy of sub lethal concentration of entomopathogenic fungi on the feeding and reproduction of Spodoptera litura
}

\author{
P. Vinayaga Moorthi ${ }^{1^{*}}$ (D, C. Balasubramanian ${ }^{1}$, S. Selvarani ${ }^{1}$ and A. Radha ${ }^{2}$
}

${ }^{*}$ Correspondence: vinayputhu@gmail.com

${ }^{1} \mathrm{PG}$ and Research

Department of Zoology,

Thiagarajar College

(Autonomous), Madurai 625

009, Tamil Nadu, India

Full list of author information

is available at the end of the article

\begin{abstract}
In the present investigation, impact of sub lethal concentrations of entomopathogenic fungi, namely Isaria fumosorosea, Beauveria bassiana and Paecilomyces variotii, secondary metabolite on feeding, growth, fecundity and hatchability of Spodoptera litura was performed. The S. litura treated with I. fumosorosea and B. bassiana metabolites exhibited renounced food consumption. The growth rate of treated $S$. litura with metabolite of I. fumosorosea had drastic reduction. In the case of approximate digestibility (AD), maximum impact was established by the I. fumosorosea isolate, which significantly reduced the approximate digestibility of the IV and V instar larvae. The III instar larvae of S. litura treated with I. fumosorosea metabolite showed significantly lower efficiency of conversion of digested food (ECD) and efficiency of conversion of ingested food (ECI) values than IV and V instars. However the performance of metabolites on fecundity and hatchability of S. litura was immense. Therefore, metabolites of I. fumosorosea could be reliable biocontrol agent, which has been highly recommended for $S$. litura management in commercial crops.
\end{abstract}

Keywords: Spodoptera litura, Isaria fumosorosea, Paecilomyces variotii, Beauveria bassiana, Growth rate, Secondary metabolite

\section{Background}

Entomopathogenic fungi, a group of microbial pest control agents, are natural insect pathogens regulating the insect population in an environment. It has been widely employed for the control of major insect pest and currently 700 species have been reported as entomopathogenic (Suganya and Selvanarayanan 2010). There are several insect pathogens, like Beauveria bassiana, Metarhizium anisopliae, Isaria fumosorosea, Verticillium lecanii and Nomuraea rileyi have been found to be promising in the control of several agricultural insect pests (Lingappa et al. 2005). The invasion of these fungi, during pathogenesis has been facilitated by enzymes but it has been strongly defended by the insect's cellular and humoral reaction. In climax, the insect barrier has been perfectly broken by the fungi by its enzymes and they started growing inside the hemolymph, where toxins like oosporein, beauverin and destruxin were secreted. The studies on role of enzyme in pathogenicity was studied enormously, while the release of secondary soluble fungal toxin during post penetration event has been detailed very little

(C) 2015 Vinayaga Moorthi et al. This article is distributed under the terms of the Creative Commons Attribution 4.0 International License (http://creativecommons.org/licenses/by/4.0/), which permits unrestricted use, distribution, and reproduction in any medium, provided you give appropriate credit to the original author(s) and the source, provide a link to the Creative Commons license, and indicate if changes were made. 
(Ortiz-Urquiza et al. 2010). Robert (1981) provided a complete overview on these fungal toxins. According to Wang et al. (2007) studies, it has been observed that, the fungal metabolites are potential insecticide against insect pest. Thomsen and Eilenberg (2000) stated that the lepidopteran insects are vulnerable to the destruxins. In support of this, $\mathrm{Hu}$ et al. (2007) stated that, the secondary metabolites produced by the entomopathogenic fungi particularly $M$. anisopliae, were toxic to Spodoptera litura. Therefore, the present study, aims to study the role of secondary metabolite of entomopathogenic fungi on the feeding, growth and development of S. litura.

\section{Results}

\section{Isolation of entomopathogenic fungi}

Entomopathogenic fungi were isolated from the rhizosphere soil collected from Kalloorani, (N9²8.575' E78 09.96) Virudhunagar District, Tamil Nadu, India. It was identified as Isaria fumosorosea, Beauveria bassiana (JX481967) and Paecilomyces variotii (JX481968) based on the Internal Transcript Spacer (ITS) sequencing.

\section{Screening of secondary metabolites}

The selected entomopathogenic fungi were subjected to solvent extraction (Ethyl acetate) for the isolation of active secondary metabolites. The extracts of the entomopathogenic fungi were subjected to study the Rf value, by separating them by using TLC and were observed under UV trans-illuminator and ninhydrin spray.

\section{Feeding experiment}

Different sub lethal concentrations were used for the feeding experiment study against S. litura in in vitro. The feeding experiment was performed on different parameters such as consumption index (CI), growth rate (GR), approximate digestibility (AD), conversion of digested food (ECD) and conversion of Ingested food (ECI) (Tables 1, 2, 3). The one tailed $\mathrm{t}$ test analysis report was presented in Table 4 .

\section{Feeding experiment}

The S. litura treated with I. fumosorosea and B. bassiana fractions exhibited reduced food consumption. I. fumosorosea fraction diminished the consumption efficiency at the mean difference of $0.035,0.582$ and 0.692 with respect to III, IV and V instar larvae of S. litura (Table 1) with respect from control to 1, 2, 3, 4 ppm accordingly. The calculated $\mathrm{CD}(0.05 \%)(0.002,0.002$ and 0.002$)$ was comparatively lower than that of the mean difference $(0.004,0.699$ and 0.765$)$ which implies the significant difference between control and treatment. The GR of treated S. litura with fractions of I. fumosorosea had drastic reduction in III, IV and V instar larvae ranged from 0.193 (control) to 0.180 (4 ppm) $\mathrm{mg}$ dry $\mathrm{wt}^{-1}$ live larvae ${ }^{-1}$; 0.198 (control) to 0.185 (4 ppm) ${\mathrm{mg} \mathrm{dry} \mathrm{wt}^{-1} \text { live larva }}^{-1}$ and 0.201 (control) to $0.181(4 \mathrm{ppm}) \mathrm{mg} \mathrm{dry} \mathrm{wt}^{-1}$ live larva ${ }^{-1}$. The mean difference of the growth rate of the control and treatment was $0.004,0.013$ and 0.006 , which was higher than the calculated CD value (0.05\% level) $(0.002,0.002$ and 0.003$)$. Similarly, in the $P$. varioti isolate, there was a sharp decrease in the growth rate observed (Table 2). The reduction in terms of weight was $0.07,0.010$ and $0.20 \mathrm{mg} \mathrm{dry} \mathrm{wt}^{-1}$ live larva $^{-1}$. The mean difference was significantly differed from control. In the case of B. bassiana, 
Table 1 Effect of ethyl acetate fraction of Isaria fumosorosea on the growth rate, consumption index and approximate digestibility of 3rd, 4th and 5th instar larvae of Spodoptera litura

\begin{tabular}{|c|c|c|c|c|c|}
\hline $\begin{array}{l}\text { I. fumosorosea } \\
\text { fraction (ppm) }\end{array}$ & $\mathrm{Cl}$ & GR & $A D$ & ECD & $\mathrm{ECl}$ \\
\hline \multicolumn{6}{|l|}{$3 r d$} \\
\hline$C$ & $0.892 \pm 0.002^{\mathrm{a}}$ & $0.193 \pm 0.001^{a}$ & $99.09 \pm 0.047^{a}$ & $23.80 \pm 0.057^{\mathrm{a}}$ & $22.30 \pm 0.085^{b}$ \\
\hline 1 & $0.310 \pm 0.017^{b}$ & $0.189 \pm 0.001^{c}$ & $97.93 \pm 0.028^{b}$ & $23.01 \pm 0.077^{b}$ & $23.07 \pm 0.069^{a}$ \\
\hline 2 & $0.226 \pm 0.003^{e}$ & $0.185 \pm 0.001^{d}$ & $97.16 \pm 0.023^{c}$ & $18.44 \pm 0.068^{c}$ & $17.92 \pm 0.024^{c}$ \\
\hline 3 & $0.251 \pm 0.003^{d}$ & $0.183 \pm 0.001^{b}$ & $96.92 \pm 0.002^{d}$ & $17.89 \pm 0.029^{d}$ & $17.52 \pm 0.026^{d}$ \\
\hline 4 & $0.276 \pm 0.001^{c}$ & $0.180 \pm 0.0004^{\mathrm{a}}$ & $96.92 \pm 0.030^{d}$ & $11.00 \pm 0.081^{c}$ & $10.92 \pm 0.012^{e}$ \\
\hline CD at 0.01 & 0.006 & 0.003 & 0.134 & 0.067 & 0.044 \\
\hline CD at 0.05 & 0.004 & 0.002 & 0.092 & 0.046 & 0.030 \\
\hline \multicolumn{6}{|l|}{ 4th } \\
\hline$C$ & $0.926 \pm 0.001^{a}$ & $0.198 \pm 0.0008^{\mathrm{a}}$ & $98.71 \pm 0.123^{a}$ & $96.52 \pm 0.098^{a}$ & $99.23 \pm 0.183^{a}$ \\
\hline 1 & $0.147 \pm 0.001^{e}$ & $0.197 \pm 0.0008^{b}$ & $95.86 \pm 0.050^{b}$ & $95.46 \pm 0.098^{a}$ & $99.14 \pm 0.446^{a}$ \\
\hline 2 & $0.280 \pm 0.012^{b}$ & $0.192 \pm 0.0008^{c}$ & $91.12 \pm 0.138^{c}$ & $95.34 \pm 0.014^{\mathrm{a}}$ & $99.04^{a} \pm 0.438^{b}$ \\
\hline 3 & $0.247 \pm 0.001^{c}$ & $0.187 \pm 0.0008^{c}$ & $90.32 \pm 0.106^{d}$ & $94.36 \pm 0.094^{a}$ & $98.91 \pm 0.116^{b}$ \\
\hline 4 & $0.234 \pm 0.002^{d}$ & $0.185 \pm 0.001^{d}$ & $89.52 \pm 0.077^{e}$ & $80.00 \pm 0.172^{b}$ & $74.17 \pm 0.130^{c}$ \\
\hline CD at 0.01 & 0.003 & 0.005 & 0.126 & 1.79 & 1.334 \\
\hline CD at 0.05 & 0.002 & 0.002 & 0.087 & 1.27 & 0.917 \\
\hline \multicolumn{6}{|l|}{ 5th } \\
\hline$C$ & $1.112 \pm 0.003^{\mathrm{a}}$ & $0.201 \pm 0.0008^{\mathrm{a}}$ & $97.34 \pm 0.046^{\mathrm{a}}$ & $97.92 \pm 0.069^{d}$ & $99.54 \pm 0.087^{a}$ \\
\hline 1 & $1.077 \pm 0.020^{b}$ & $0.195 \pm 0.001^{b}$ & $91.34 \pm 0.046^{b}$ & $96.72 \pm 0.111^{b}$ & $99.53 \pm 0.033^{a}$ \\
\hline 2 & $1.060 \pm 0.020^{c}$ & $0.189 \pm 0.001^{c}$ & $90.32 \pm 0.053^{c}$ & $96.24 \pm 0.086^{c}$ & $99.25 \pm 0.082^{b}$ \\
\hline 3 & $0.867 \pm 0.002^{d}$ & $0.187 \pm 0.001^{c}$ & $89.17 \pm 0.058^{d}$ & $96.47 \pm 0.077^{a}$ & $99.17 \pm 0.045^{c}$ \\
\hline 4 & $0.838 \pm 0.003^{e}$ & $0.181 \pm 0.001^{c}$ & $88.05 \pm 0.061^{\mathrm{e}}$ & $96.87 \pm 0.048^{e}$ & $99.03 \pm 0.073^{d}$ \\
\hline CD at 0.01 & 0.001 & 0.004 & 0.023 & 0.050 & 0.147 \\
\hline CD at 0.05 & 0.001 & 0.003 & 0.016 & 0.035 & 0.105 \\
\hline
\end{tabular}

$C l$ consumption index, $G R$ growth rate, $A D$ approximate digestibility, $E C D$ efficiency of conversion of digested food, $E C I$ efficiency of conversion of ingested food

a,b,c,d $C D$ critical difference values were significant at 0.01 and $0.05 \%$ level

the reduction of growth rate was found higher in 3rd instar larvae, whereas it become remain the same in the 4 th and 5 th instar larvae $\left(0.020 \mathrm{mg}\right.$ dry $\mathrm{wt}^{-1}$ live larva $\left.{ }^{-1}\right)$ (Table 2). The mean difference of the growth rate between the control and treatment was $0.004,0.009$ and 0.011 . It was higher than the calculated $\mathrm{CD}(0.05 \%$ level $)$ value $(0.002$, 0.003 and 0.001 ), which implies the significant difference in the growth rate of control and experiment.

The AD sharply decreased with increasing the concentration. The maximum impact was established by the I. fumosorosea isolate, which significantly reduced the AD of the IV and V instar larvae. The III instar exhibited over $90 \%$ AD which declined sharply in the IV and V instars to a maximum of 88.05 and $83.33 \%$. The mean difference of the control and treatment with respect to III, IV and V instar larvae was 1.16, 2.85 and 0.006. Similar reduction was not observed in $P$. variotii, while $B$. bassiana isolates exhibited the similar pattern of reduction from III to V instar larvae. The AD of the $P$. variotii and $B$. bassiana isolate from III to V instar at $4 \mathrm{ppm}$ ranged from 83.33 (Table 2) to $91.34 \%$ (Table 2) and 92.45 (Table 3) to $86.33 \%$ (Table 3) respectively. The P. variotii treated V instar larvae showed healthy by maintain over $90 \% \mathrm{AD}$. The $\mathrm{CD}$ values of the $P$. variotii 
Table 2 Effect of fraction of Paecilomyces variotii on the growth rate, consumption index and approximate digestibility 3rd, 4th and 5th instar larvae of Spodoptera litura

\begin{tabular}{|c|c|c|c|c|c|}
\hline $\begin{array}{l}\text { P. variotii fraction } \\
\text { (ppm) }\end{array}$ & $\mathrm{Cl}$ & GR & $A D$ & ECD & $\mathrm{ECl}$ \\
\hline \multicolumn{6}{|l|}{$3 r d$} \\
\hline$C$ & $0.867 \pm 0.003^{\mathrm{a}}$ & $0.200 \pm 0.001^{\mathrm{a}}$ & $96.92 \pm 0.038^{a}$ & $94.27 \pm 0.014^{a}$ & $98.11 \pm 0.04^{\mathrm{a}}$ \\
\hline 1 & $0.694 \pm 0.011^{b}$ & $0.196 \pm 0.001^{b}$ & $89.47 \pm 0.089^{b}$ & $93.25 \pm 0.29^{b}$ & $97.61 \pm 0.11^{b}$ \\
\hline 2 & $0.615 \pm 0.61^{c}$ & $0.194 \pm 0.002^{c}$ & $88.67 \pm 0.036^{b}$ & $92.46 \pm 0.18^{d}$ & $97.36 \pm 0.17^{c}$ \\
\hline 3 & $0.580 \pm 0.012^{d}$ & $0.194 \pm 0.001^{c}$ & $85.71 \pm 0.084^{b}$ & $92.87 \pm 0.17^{c}$ & $97.22 \pm 0.34^{d}$ \\
\hline 4 & $0.471 \pm 0.003^{e}$ & $0.193 \pm 0.002^{c}$ & $83.33 \pm 0.019^{c}$ & $23.01 \pm 0.39^{e}$ & $22.30 \pm 0.06^{\mathrm{e}}$ \\
\hline CD at 0.01 & 0.006 & 0.003 & 2.397 & 0.043 & 0.042 \\
\hline CD at 0.05 & 0.045 & 0.002 & 1.648 & 0.030 & 0.029 \\
\hline \multicolumn{6}{|l|}{ 4th } \\
\hline$C$ & $0.926 \pm 0.002^{\mathrm{a}}$ & $0.207 \pm 0.000^{a}$ & $92.71 \pm 0.123^{a}$ & $91.32 \pm 0.026^{a}$ & $99.54 \pm 0.098^{a}$ \\
\hline 1 & $0.227 \pm 0.000^{b}$ & $0.198 \pm 0.001^{b}$ & $91.33 \pm 0.026^{d}$ & $89.54 \pm 0.086^{b}$ & $99.54 \pm 0.192^{\mathrm{a}}$ \\
\hline 2 & $0.190 \pm 0.003^{c}$ & $0.192 \pm 0.001^{c}$ & $89.74 \pm 0.070^{b}$ & $89.10 \pm 0.070^{b}$ & $99.43 \pm 0.184^{\mathrm{ab}}$ \\
\hline 3 & $0.140 \pm 0.004^{e}$ & $0.191 \pm 0.000^{d}$ & $89.33 \pm 0.026^{c}$ & $87.64 \pm 0.026^{c}$ & $99.36 \pm 0.061^{\mathrm{a}}$ \\
\hline 4 & $0.161 \pm 0.001^{d}$ & $0.187 \pm 0.000^{e}$ & $87.64 \pm 0.049^{e}$ & $80.50 \pm 0.102^{d}$ & $74.17 \pm 0.050^{c}$ \\
\hline CD at 0.01 & 0.003 & 0.008 & 1.533 & 0.035 & 0.162 \\
\hline CD at 0.05 & 0.002 & 0.006 & 1.054 & 0.024 & 0.111 \\
\hline \multicolumn{6}{|l|}{5 th } \\
\hline$C$ & $1.006 \pm 0.002^{\mathrm{a}}$ & $0.215 \pm 0.000^{\mathrm{a}}$ & $94.62 \pm 0.066^{a}$ & $96.47 \pm 0.104^{\mathrm{a}}$ & $99.46 \pm 0.053^{a}$ \\
\hline 1 & $0.241 \pm 0.001^{b}$ & $0.192 \pm 0.001^{b}$ & $93.07 \pm 0.041^{b}$ & $96.37 \pm 0.184^{b}$ & $99.09 \pm 0.024^{c}$ \\
\hline 2 & $0.115 \pm 0.001^{d}$ & $0.190 \pm 0.002^{c}$ & $92.68 \pm 0.085^{c}$ & $95.47 \pm 0.086^{c}$ & $99.38 \pm 0.046^{b}$ \\
\hline 3 & $0.107 \pm 0.002^{e}$ & $0.187 \pm 0.000^{d}$ & $92.02 \pm 0.390^{d}$ & $95.46 \pm 0.140^{c}$ & $99.03 \pm 0.045^{d}$ \\
\hline 4 & $0.139 \pm 0.001^{c}$ & $0.175 \pm 0.000^{e}$ & $91.34 \pm 0.057^{e}$ & $94.36 \pm 0.180^{d}$ & $98.78 \pm 0.037^{e}$ \\
\hline CD at 0.01 & 0.003 & 0.008 & 0.036 & 0.117 & 0.120 \\
\hline CD at 0.05 & 0.002 & 0.006 & 0.025 & 0.080 & 0.083 \\
\hline
\end{tabular}

$C l$ consumption index, $G R$ growth rate, $A D$ approximate digestibility, $E C D$ efficiency of conversion of digested food, $E C I$ efficiency of conversion of ingested food

$a, b, c, d$ CD critical difference values were significant at 0.01 and $0.05 \%$ level

and $B$. bassiana stated that, the AD of the tested instars was significantly differed from control group.

The III instar larvae of S. litura treated with I. fumosorosea toxin showed significantly lower ECD and ECI values than IV and V instars (Table 1). The similar impact was also observed in the III instar larvae (Table 2) treated with fraction of P. variotii (ECD and ECI) and B. bassiana (Table 3) (ECD and ECI). Exceptionally, V instar larvae of S. litura treated with $B$. bassiana had outrageous impact and have least conversion efficiency of 23.01 and $22.90 \%$ with respect to ECD and ECI. There was a significant difference in the control and treatment was observed for ECD and ECI values of $S$. litura treated with $P$. variotii and B. bassiana.

\section{Effect of ethyl acetate fraction on the fecundity and hatchability}

The fractions of EPF had adverse effect on egg laying as well as growth stages of $S$. litura. The fecundity of $S$. litura inversely proportional to the concentration of the fraction of I. fumosorosea used (Table 5; Fig. 1). The fecundity of the S. litura treated with I. fumosorosea fraction drastically reduced since lowest concentrations recorded

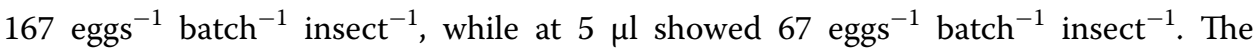


Table 3 Effect of ethyl acetate fraction of Beauveria bassiana on the growth rate, consumption index and approximate digestibility of 3rd, 4th and 5th instar larvae of Spodoptera litura

\begin{tabular}{|c|c|c|c|c|c|}
\hline $\begin{array}{l}\text { B. bassiana fraction } \\
\text { (ppm) }\end{array}$ & $\mathrm{Cl}$ & GR & $A D$ & ECD & $\mathrm{ECl}$ \\
\hline \multicolumn{6}{|l|}{$3 r d$} \\
\hline C & $1.94 \pm 0.002^{\mathrm{a}}$ & $0.199 \pm 0.003^{\mathrm{ab}}$ & $99.01 \pm 0.085^{a}$ & $23.01 \pm 0.100^{\mathrm{a}}$ & $22.90 \pm 0.065^{b}$ \\
\hline 1 & $1.77 \pm 0.001^{b}$ & $0.195 \pm 0.000^{c}$ & $97.93 \pm 0.057^{b}$ & $22.93 \pm 0.156^{a}$ & $98.00 \pm 0.054^{\mathrm{a}}$ \\
\hline 2 & $1.42 \pm 0.001^{c}$ & $0.191 \pm 0.001^{b}$ & $96.92 \pm 0.041^{c}$ & $14.5 \pm 0.143^{b}$ & $14.70 \pm 0.037^{c}$ \\
\hline 3 & $1.36 \pm 0.003^{d}$ & $0.189 \pm 0.001^{\mathrm{ab}}$ & $96.26 \pm 0.150^{d}$ & $14.8 \pm 0.132^{b}$ & $14.70 \pm 0.022^{c}$ \\
\hline 4 & $0.867 \pm 0.002^{c}$ & $0.176 \pm 0.000^{c}$ & $92.45 \pm 0.040^{e}$ & $12.24 \pm 0.190^{c}$ & $11.33 \pm 0.066^{d}$ \\
\hline CD at 0.01 & 0.009 & 0.003 & 0.089 & 0.324 & 0.310 \\
\hline CD at 0.05 & 0.006 & 0.002 & 0.061 & 0.223 & 0.213 \\
\hline \multicolumn{6}{|l|}{ 4th } \\
\hline C & $1.017 \pm 0.002^{\mathrm{a}}$ & $0.201 \pm 0.002^{c}$ & $96.92 \pm 0.061^{\mathrm{a}}$ & $83.11 \pm 0.123^{a}$ & $81.90 \pm 0.046^{a}$ \\
\hline 1 & $0.624 \pm 0.000^{b}$ & $0.192 \pm 0.000^{b}$ & $96.11 \pm 0.021^{b}$ & $69.00 \pm 0.141^{a}$ & $64.18 \pm 0.047^{a}$ \\
\hline 2 & $0.310 \pm 0.000^{e}$ & $0.189 \pm 0.001^{\mathrm{ab}}$ & $93.45 \pm 0.034^{d}$ & $68.22 \pm 0.138^{\mathrm{a}}$ & $62.93 \pm 0.047^{b}$ \\
\hline 3 & $0.317 \pm 0.003^{d}$ & $0.187 \pm 0.000^{\mathrm{a}}$ & $89.24 \pm 0.032^{e}$ & $58.11 \pm 0.147^{b}$ & $55.28 \pm 0.094^{c}$ \\
\hline 4 & $0.361 \pm 0.001^{c}$ & $0.171 \pm 0.001^{b}$ & $87.12 \pm 0.078^{c}$ & $33.33 \pm 0.132^{c}$ & $32.00 \pm 0.074^{d}$ \\
\hline CD at 0.01 & 0.001 & 0.005 & 0.002 & 0.130 & 0.002 \\
\hline CD at 0.05 & 0.001 & 0.003 & 0.001 & 0.089 & 0.002 \\
\hline \multicolumn{6}{|l|}{ 5th } \\
\hline C & $1.091 \pm 0.002^{\mathrm{a}}$ & $0.202 \pm 0.002^{\mathrm{a}}$ & $96.92 \pm 0.047^{a}$ & $98.42 \pm 0.111^{a}$ & $93.24 \pm 0.047^{b}$ \\
\hline 1 & $0.297 \pm 0.000^{b}$ & $0.191 \pm 0.001^{b}$ & $88.80 \pm 0.047^{b}$ & $94.36 \pm 0.145^{c}$ & $83.0 \pm 0.0081^{c}$ \\
\hline 2 & $0.229 \pm 0.002^{c}$ & $0.190 \pm 0.001^{b}$ & $87.75 \pm 0.081^{c}$ & $76.36 \pm 0.156^{b}$ & $71.26 \pm 0.009^{a}$ \\
\hline 3 & $0.183 \pm 0.002^{e}$ & $0.186 \pm 0.002^{\mathrm{ab}}$ & $86.33 \pm 0.094^{d}$ & $54.36 \pm 0.141_{b}$ & $49.23 \pm 0.081^{a}$ \\
\hline 4 & $0.217 \pm 0.006^{d}$ & $0.169 \pm 0.002^{c}$ & $86.33 \pm 0.094^{d}$ & $23.01 \pm 0.127^{d}$ & $22.90 \pm 0.047^{d}$ \\
\hline CD at 0.01 & 0.002 & 0.003 & 0.039 & 0.958 & 1.974 \\
\hline CD at 0.05 & 0.001 & 0.001 & 0.027 & 0.657 & 1.357 \\
\hline
\end{tabular}

$C l$ consumption index, $G R$ growth rate, $A D$ approximate digestibility, $E C D$ efficiency of conversion of digested food, $E C I$ efficiency of conversion of ingested food

a,b,c,d $C D$ critical difference values were significant at 0.01 and $0.05 \%$ level

mean difference between the control and experiment was 8.07, which was higher than the calculated $C D$ value ( 0.049 and 0.034 at 0.01 and $0.05 \%$ respectively). The difference in fecundity found between the lower to higher concentration was 100 eggs batch ${ }^{-1}$ insect $^{-1}$. No such reduction in the egg laying was observed in the case of P. variotii (Table 5) and B. bassiana (Table 5) treated S. litura. Mean while, fecundity reduction contributed by $P$. variotii and $B$. bassiana treated instars were significant at 0.01 (0.028) and $0.05 \%(0.019)$ level. The egg laid by the S. litura treated with B. bassiana was 136 eggs bactch ${ }^{-1}$ insect $^{-1}$, which was little higher than $P$. variotii treated instar. Further, an average of $55 \%$ reduction in hatchability was observed in I. fumosorosea, $P$. variotii and B. bassiana. In comparison to the control and experimental group with calculated $C D$ value ( 0.079 and 0.056 with respect to 0.01 and $0.05 \%$ ) implies the existence of significant difference in the treated group. Similarly, $76 \%$ reduction of pupation was observed in I. fumosorosea fraction treated groups whereas P. variotii and B. bassiana contributed 48 and $68 \%$ respectively. The mean difference and calculated CD at $0.01 \%$ (3.906) and $0.05 \%$ (2.746) showed that, the treated group was significantly differed. Similarly higher number of malformed pupae was observed in B. bassiana followed by 


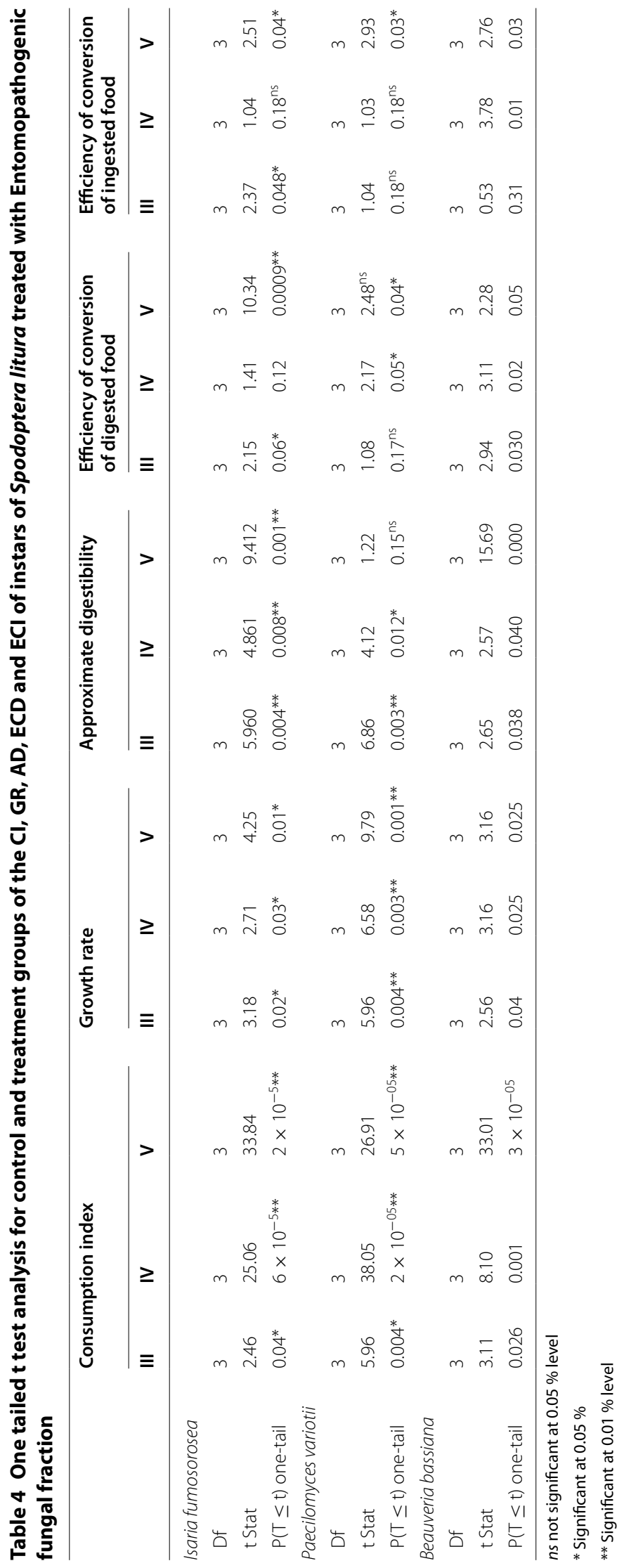


Table 5 Effect of fraction of entomopathogenic fungi on the fecundity and hatchability of against Spodoptera litura

\begin{tabular}{|c|c|c|c|c|c|c|}
\hline Fungi & $\begin{array}{l}\text { Concen- } \\
\text { tration } \\
\text { (ppm) }\end{array}$ & $\begin{array}{l}\text { Eggs laid/ } \\
\text { batch }\end{array}$ & $\begin{array}{l}\text { Eggs } \\
\text { hatched }\end{array}$ & $\begin{array}{l}\text { Pupa } \\
\text { emerged }\end{array}$ & $\begin{array}{l}\text { Malformed } \\
\text { pupa }\end{array}$ & $\begin{array}{l}\text { Adult } \\
\text { emerged }\end{array}$ \\
\hline \multirow{7}{*}{$\begin{array}{l}\text { Isaria } \\
\text { fumosoro- } \\
\text { sea }\end{array}$} & Control & $176.04 \pm 0.049^{a}$ & $95.45 \pm 0.106^{a}$ & $96.00 \pm 0.047^{a}$ & $0.00^{\mathrm{a}}$ & $92.00 \pm 0.433^{a}$ \\
\hline & 1 & $167.97 \pm 0.055^{b}$ & $94.61 \pm 0.120^{b}$ & $76.00 \pm 0.064^{b}$ & $4.00 \pm 0.047^{b}$ & $72.00 \pm 0.047^{b}$ \\
\hline & 2 & $124.33 \pm 0.085^{c}$ & $87.09 \pm 0.180^{c}$ & $72.00 \pm 0.623^{c}$ & $4.00 \pm 0.117^{c}$ & $68.00 \pm 0.004^{c}$ \\
\hline & 3 & $84.03 \pm 0.057^{d}$ & $42.00 \pm 0.047^{d}$ & $28.00 \pm 0.458^{d}$ & $12.00 \pm 0.108^{d}$ & $16.00 \pm 0.816^{d}$ \\
\hline & 4 & $67.03 \pm 0.057^{e}$ & $40.29 \pm 0.064^{e}$ & $24.00 \pm 0.204^{e}$ & $12.00 \pm 0.131^{e}$ & $12.00 \pm 0.816^{\mathrm{e}}$ \\
\hline & CD at 0.01 & 0.049 & 0.028 & 0.079 & 0.353 & 0.101 \\
\hline & CD at 0.05 & 0.034 & 0.019 & 0.056 & 0.248 & 0.071 \\
\hline \multirow{7}{*}{$\begin{array}{c}\text { Paecilomyces } \\
\text { variotii }\end{array}$} & Control & $148 \pm 0.020^{a}$ & $98.46 \pm 0.080^{a}$ & $98.93 \pm 0.016^{a}$ & $0.33 \pm 0.471^{c}$ & $99.91 \pm 0.115^{a}$ \\
\hline & 1 & $118 \pm 0.612^{b}$ & $89.78 \pm 0.128^{b}$ & $84.00 \pm 0.081^{b}$ & $0.67 \pm 0.471^{c}$ & $84.00 \pm 0.084^{b}$ \\
\hline & 2 & $114 \pm 0.122^{c}$ & $72.88 \pm 0.080^{c}$ & $80.00 \pm 0.151^{c}$ & $4.00 \pm 0.365^{b}$ & $76.00 \pm 0.426^{c}$ \\
\hline & 3 & $96 \pm 0.188^{d}$ & $55.76 \pm 0.166^{d}$ & $68.00 \pm 0.147^{d}$ & $4.00 \pm 1.247^{b}$ & $60.00 \pm 0.204^{d}$ \\
\hline & 4 & $87 \pm 0.069^{e}$ & $51.04 \pm 0.376^{e}$ & $52.00 \pm 0.440^{e}$ & $8.00 \pm 0.081^{a}$ & $44.00 \pm 0.382^{e}$ \\
\hline & CD at 0.01 & 0.263 & 0.459 & 3.906 & 3.592 & 3.526 \\
\hline & CD at 0.05 & 0.143 & 0.322 & 2.746 & 2.526 & 2.479 \\
\hline \multirow{7}{*}{$\begin{array}{c}\text { Beauveria } \\
\text { bassiana }\end{array}$} & Control & $149 \pm 0.131^{a}$ & $92.61 \pm 0.201^{a}$ & $99.91 \pm 0.115^{\mathrm{a}}$ & $4.00 \pm 0.540^{c}$ & $96.00 \pm 0.358^{a}$ \\
\hline & 1 & $136 \pm 0.099^{b}$ & $86.76 \pm 0.147^{b}$ & $92.00 \pm 0.092^{b}$ & $4.00 \pm 0.071^{c}$ & $88.00 \pm 0.128^{b}$ \\
\hline & 2 & $118 \pm 0.184^{c}$ & $76.27 \pm 0.257^{c}$ & $84.00 \pm 0.154^{c}$ & $4.00 \pm 0.094^{c}$ & $80.00 \pm 0.154^{c}$ \\
\hline & 3 & $96 \pm 0.062^{d}$ & $56.25 \pm 0.277^{d}$ & $48.00 \pm 0.540^{d}$ & $18.00 \pm 0.108^{a}$ & $40.00 \pm 0.104^{d}$ \\
\hline & 4 & $84 \pm 0.201^{e}$ & $32.54 \pm 0.148^{e}$ & $32.00 \pm 0.071^{e}$ & $12.00 \pm 0.530^{b}$ & $20.00 \pm 0.157^{e}$ \\
\hline & CD at 0.01 & 0.331 & 0.529 & 0.484 & 0.391 & 0.786 \\
\hline & CD at 0.05 & 0.200 & 0.319 & 0.292 & 0.235 & 0.474 \\
\hline
\end{tabular}

Values are mean $\pm S D$ of three replication

a,b,c,d $C D$ critical difference values were significant at 0.01 and $0.05 \%$ level

I. fumosorosea and $P$. variotii. In this, the effect of $1 \mathrm{ppm}$ concentration of $B$. bassiana on the mean malformed pupae $(0.67 \pm 0.047)$ was not significantly differed (3.59). A mutated crisis in the adult emergence was observed in I. fumosorosea fractions treated $S$. litura which showed $88 \%$ adult emergence over B. bassiana and $P$. variotii with respect to 80 and $66 \%$ (Fig. 1). However the performance of fraction on fecundity and hatchability of $S$. litura was immense. In addition to that, they shortened and mutated the each stage up to adult emergence in a panic and adverse way. Hence the fractions were not only pathogenic but also mutagenic to the S. litura. However, the instars treated with selected EPF showed significant difference in the treatment with respective fractions of EPF.

\section{Discussion}

In this study, the tested fractions showed good sign of infection during the life cycle of $S$. litura. Vey et al. (2001) reported the in vivo effects of fungal metabolites in insects, measured as growth depression and changes in mortality, fertility, egg viability and metamorphosis. In the present study, a drastic decline in food consumption was observed with fraction of I. fumosorosea compared to B. bassiana and P. variotii. It was well supported by Tefera and Pringle (2003) who observed that, the significant reduction in consumption has been attributed to the production of toxic substances by the entomopathogenic fungi inside the host that lead to mechanical disruption in the insect structural integrity. 

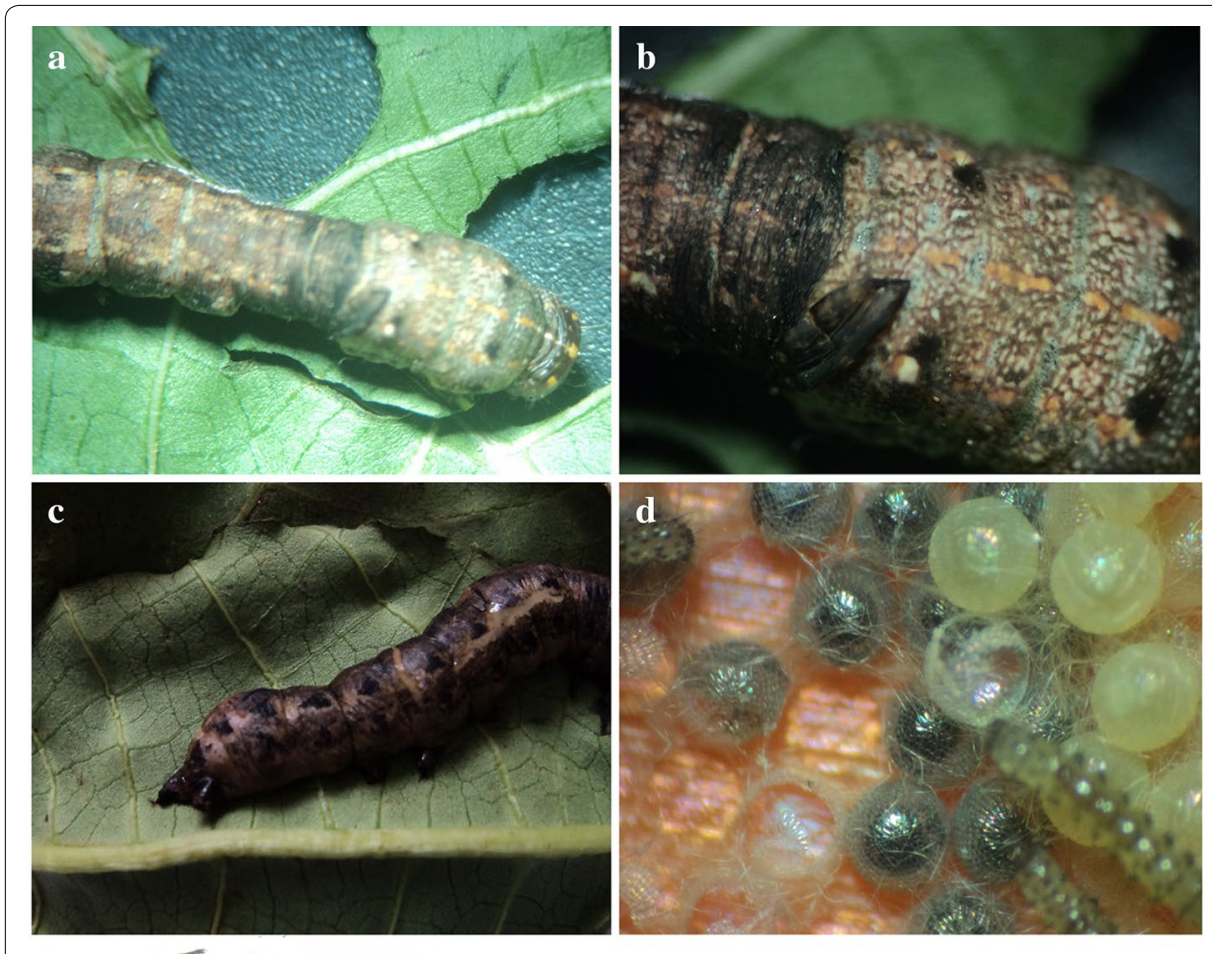

e

f
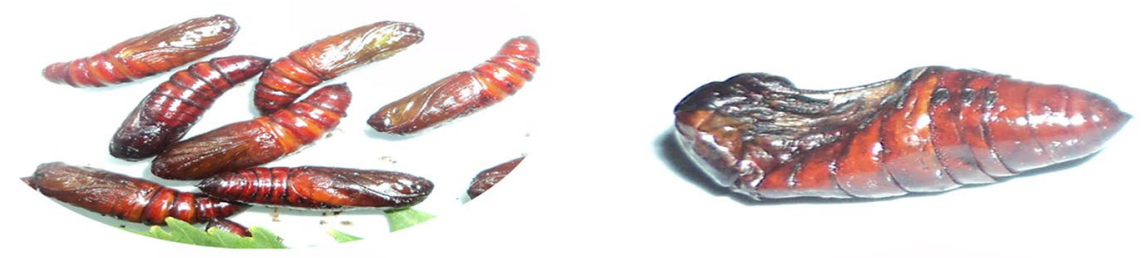

g

$\mathbf{h}$
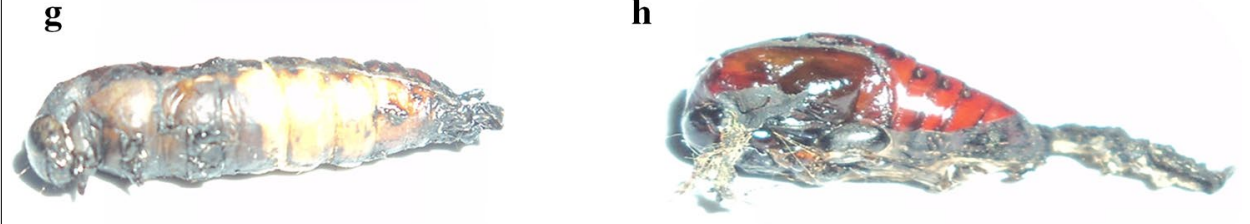

Fig. 1 Impact sub lethal dose of secondary metabolite of Isaria fumosorosea on larvae and pupa and egg of Spodoptera litura. $\mathbf{a}, \mathbf{b}$ Infected larvae and its enlarged image; c dead larvae; $\mathbf{d}$ unhatched eggs and hatched larvae; e pupa (control); $\mathbf{f}, \mathbf{g}, \mathbf{h}$ different type of infected pupa

The drastic reduction in food consumption in the present study was supported by Assaf et al. (2005) who stated that the reduction in feeding associated with the production of toxins by the fungus I. fumosorosea.

Sahayaraj and Tomson (2010) observed $33.34 \%$ reduction in bodyweight of Dysdercus cingulatus treated with metabolites of B. bassiana fraction 2 (BBF2). It supported the present study that, the reduction in the range of $0.02-0.010 \mathrm{mg}$ in larval weight of S. litura. Similar observation was also attained by Malarvannan et al. (2008) who found 
reduction in the larval weight of $S$. litura treated with the fractions of Argemone mexicana during development and observed the formation of shriveled pupa.

The early instar larvae of S. litura had shown normal digestion compared to control while proceeding the larvae failed to show a good sign of digestion process in terms of reduced $\mathrm{AD}$. The higher $\mathrm{AD}$ values in the early instars of infected larvae may be due to the little consumption of the treated part. Likewise, the lower AD values in the late instars were because these caterpillars consumed food indiscriminately to meet the demand for energy and nitrogen (Hussain et al. 2009). In support of the present investigation, Hussain et al. (2009) observed higher AD values in Ocinara varians larvae infected with entomopathogenic fungi compared to the healthy control. The present investigation recorded reduced conversion potential (digested as well ingested food) of the treated larvae. Slansky and Scriber (1982) found that the utilization efficiencies (ECI) of 11 predaceous insects were between 4 and $75 \%$, while in the present investigation, the isolate I. fumosorosea fraction treated larvae had shown comparatively higher reduction in ECD and ECI which ranged from 75 to $46 \%$ with respect to III to V instar larvae. In support of the present study, Sintim et al. (2009) observed $45.8 \%$ ECI value in $S$. litura when fed with artificial diet. Fraenkel (1981) states that, under suitable conditions, a growing insect could convert maximum of $2 / 3$ of its ingested food to body materials remaining will be utilized for metabolic processes.

Abnormal reduction in hatchability of eggs in I. fumosorosea treatment was in accompany with Leckie et al. (2008) observed delayed development, lower weights and high mortality of larvae of Heliothis zea when fed on diets containing mycelia of $B$. bassiana. Malarvannan et al. (2010) observed the complete arrest of fecundity by $2.4 \times 10^{7}$ spore $\mathrm{mL}^{-1}$ concentration of $B$. bassiana. Similarly, Gindin et al. (2006) reported reduction of $80-82 \%$ in the hatchability of red palm weevil adults, Rhynchophorus ferrugineus treated with B. bassiana. From this it was confirmed that, the deleterious impact of this insecticidal toxin or fraction on the larval anatomy has been noticed.

\section{Conclusions}

Surveillance of impact of fungal fraction on growth and development of S. litura was performed in the present study. Sub lethal dose of I. fumosorosea fraction had significant impact on the consumption and digestion rate of $S$. litura. There was severe damage in the midgut regions were noticed. In addition to that, the next generation seeds, the eggs, were heavily suffocated in development and thereby I. fumosorosea fraction severely reduced the hatching and thus leads to significant production of malformed pupae for the next generation. Therefore, I. fumosorosea fraction could be reliable biocontrol agent that can highly recommend for S. litura management in cotton as well as sunflower field.

\section{Methods}

\section{Isolation of entomopathogenic fungi}

One gram of soil was diluted with $10 \mathrm{ml}$ of distilled water and was serially diluted. From each dilution, $100 \mu \mathrm{L}$ was plated on Potato Dextrose Agar (PDA) medium and it was fortified with streptomycin $(10 \mathrm{mg} / 100 \mathrm{ml})$. It was allowed to grow for 7 days at $27 \pm 2{ }^{\circ} \mathrm{C}$ in the respective media. After 7 days of incubation, the fungal colony was identified and was sub-cultured in Sabaroud Dextrose Agar (SDA). In the case of cadavers, each 
cadaver is carefully held with a light forceps and the conidia drawn slowly into a vial using a 00 camlin brush. Five milli-gram of dry spore was taken and added with $10 \mathrm{ml}$ of sterile $0.02 \%$ tween 80 solution. The sterilized SDA medium was transferred into sterile petridishes and test tubes that were then inoculated with pure conidia of entomopathogenic fungi by streak plate method (Haraprasad et al. 2001) The isolated fungi were transferred on to Potato Dextrose Agar (Hi-Media, India) petri dishes $(9 \mathrm{~cm}$ in diameter) (Borosil ${ }^{\circledR}$ ) and incubated at $25^{\circ} \mathrm{C}$ for $1-2$ week to produce conidia which is used as inoculums for the further study.

\section{Screening of secondary metabolites}

After 2 weeks of incubation, dense sporulated PDA plate was used for harvesting the inoculum preparation. The plate was flooded with $20 \mathrm{~mL}$ of sterile distilled water supplemented with $0.02 \%$ tween 80 (Hi-Media, India) and scraped with stainless steel spatula (Hi -Media, India). It was then filtered through muslin cloth and the resulted spore solution was subjected for spore count using Haemocytometer. The spore concentration was then adjusted to $1 \times 10^{8}$ and $1 \mathrm{~mL}$ from this stock was poured into the Potato dextrose broth (PDB) (Hi-Media, India) for secondary metabolite production. After 14 days of incubation, crude extracts of the cultured broth were obtained following the method reported by $\mathrm{Hu}$ et al. (2007) with minor modification. The thick mycelia mat was removed and culture medium was harvested and centrifuged (Remi, India) at $8000 \mathrm{rpm}$ for $10 \mathrm{~min}$. The supernatant was extracted with ethyl acetate (Sample: Ethyl acetate $=5: 2, \mathrm{v} / \mathrm{v}$ ) and the organic phase was evaporated by placing it in incubator at $40{ }^{\circ} \mathrm{C}$. The concentrate was diluted with 4 times volume of water and incubated at $4{ }^{\circ} \mathrm{C}$ overnight until the precipitation was observed. Finally, dried precipitate was used for bioassay as secondary metabolite. The precipitate was dissolved in ethyl acetate and used for feeding experiment.

\section{Feeding experiment}

The first instar larva of S. litura was separated from stock culture and fed with Ricinus communis leaves ad libitum. After the larvae reached the III instar, the initial weight of the larvae and leaves provided to them were calculated using digital balance. The leaf consumption rate was calculated from III to V instar along with the growth rate of the larvae. The faecal matter of these larvae was also collected at each stages were dried and weighed from which the a $P$. variotii milation rate of the larvae was calculated. It was adopted to larvae of $S$. litura to calculate its consumption index (CI), growth rate (GR), approximate digestibility (AD), efficiency of conversion of digested food (ECD) and efficiency of conversion of ingested food (ECI) by gravimetric analysis (Waldbauer 1968) by using the following formula.

\section{Consumption index $(\mathrm{Cl})$}

Consumption index $(\mathrm{CI})$ or the rate of feeding relative to the weight of the insect in a definite time can be expressed as:

$$
\mathrm{CI}=\frac{\mathrm{F}}{\mathrm{TA}}
$$


where, $\mathrm{F}$ is the weight of food eaten; $\mathrm{A}$ is the mean weight of insect during the feeding period, $\mathrm{T}$ is the duration of the feeding period (Days)

\section{Growth rate (GR)}

This measurement explains the rate at which the digested matter is available to the insect during the experimental period.

$\mathrm{GR}=\frac{\text { Weight gained by the insect }}{\text { Duration of feeding period (Days) } \times(\text { Mean weight of insect during the feeding period })}$

\section{Approximate digestibility (AD)}

$$
\mathrm{AD}=\frac{\text { Weight of food ingested }- \text { weight of faeces }}{\text { Weight of food ingested }} \times 100
$$

Earlier workers have used to call approximate digestibility as "co-efficient of utilization", "coefficient of digestibility" and "degree of absorption" for express P. variotiing the digestibility of food material. Waldbauer (1968) pointed out that this measure is misleading and should be referred to as "approximate digestibility".

\section{Efficiency of conversion of digested food (ECD)}

$$
\mathrm{ECD}=\frac{\text { Weight gained by the insect }}{\text { Weight of food digested }} \times 100
$$

The amount of food digested can be calculated by subtracting the weight of faeces from the weight of food ingested. This index has also been termed by some workers as "coefficient of growth".

\section{Efficiency of conversion of ingested food (ECl)}

Efficiency of conversion of ingested food measurement indicate the overall efficiency of the insect to utilize the food for growth.

$$
\mathrm{ECI}=\frac{\text { Weight gained by the insect }}{\text { Weight of food ingested }} \times 100
$$

\section{Statistical analysis}

Data of fecundity and hatchability both control and treatment was subjected to one tailed $t$ test by using Statistical Packages for Social Sciences version 17. The critical difference $(C D)$ value was calculated by using the software WASP 1.0.

Authors' contributions

PVM and CB designed this study and PVM executed the study. CB, SS and AR collected the reference data and corrected the manuscript. PVM wrote the manuscript. All authors read and approved the final manuscript.

Author details

${ }^{1}$ PG and Research Department of Zoology, Thiagarajar College (Autonomous), Madurai 625 009, Tamil Nadu, India.

${ }^{2}$ Kunthavai Nacchiyar Government Arts College for Women (Autonomous), Thanjavur, India. 


\section{Acknowledgements}

Authors thank the President, Madam Secretary, Principal, Thiagarajar College, Madurai, Tamil Nadu, India for the well established laboratory facilities. Dr. (Mrs) B. Nalina Vinayaga Moorthi, for her encouragement and proof correction.

\section{Competing interests}

The authors declare that they have no competing interests.

Received: 11 June 2015 Accepted: 14 October 2015

Published online: 06 November 2015

\section{References}

Assaf A, Cerda-Garcia-Rojas C, de la Torre M (2005) Isolation of dipicolinic acid as an insecticidal toxin from Paecilomyces fumosoroseus. Appl Microbiol Biotechnol 68:542-547

Fraenkel G (1981) Food conversion efficiency by fleshfly larvae, Sacrophaga bullata. Physiol Entomol 6:157-160

Gindin G, Levski S, Glazer I, Soroker V (2006) Evaluation of the entomopathogenic fungi, Metarhizium anisopliae and Beauveria bassiana against the red palm weevil, Rhynchophorus ferrugineus. Phytoparasitica 34:370-379

Haraprasad N, Niranjana SR, Prakash HS, Shetty HS, Wahab S (2001) Beauveria bassiana a potential mycopesticide for the efficient control of coffee berry borer, Hypothenemus hampei (Ferrari) in India. Biocontrol Sci Technol 11:251-260

Hu QB, Ren SX, An XC, Qian MH (2007) Insecticidal activity influence of destruxins on the pathogenicity of Paecilomyces javanicus against Spodoptera litura. J Appl Entomol 131:262-268

Hussain A, Tian MY, He YR, Ahmed S (2009) Entomopathogenic fungi disturbed the larval growth and feeding performance of Ocinara varians (Lepidoptera: Bombycidae) larvae. J Insect Sci 16:511-517

Leckie BM, Ownley BH, Pereira RM, Klingeman WE, Jones CJ, Gwinn KD (2008) Mycelia and spent fermentation broth of Beauveria bassiana incorporated into synthetic diets affect mortality, growth and development of larval Helicoverpa zea (Lepidoptera: Noctuidae). Biocontrol Sci Technol 18:697-710

Lingappa S, Saxena H, Devi Vimala PS (2005) Role of biocontrol agents in management of Helicoverpa armigera (Hubner). In: Saxena H, Rai AB, Ahmad R, Gupta S (eds) Recent advances in Helicoverpa armigera management. Indian Society of Pulses Research and development, IIPR, Kanpur, pp 159-184

Malarvannan S, Giridharan R, Sekar S, Prabavathy VR, Nair S (2008) Bioefficacy of Crude and Fractions of Argemone mexicana against Tobacco Caterpillar, Spodoptera litura Fab. (Noctuidae: Lepidoptera). J Biopest 1:55-62

Malarvannan S, Murali PD, Shanthakumar SP, Sudha Nair Prabavathy VR (2010) Laboratory evaluation of the entomopathogenic fungi, Beauveria bassiana against the tobacco caterpillar, Spodoptera litura Fabricius (Noctuidae: Lepidoptera). J Biopest 3:126-131

Ortiz-Urquiza L, Riveiro-Miranda C, Santiago-Álvarez E, Quesada-Moraga (2010) Insect-toxic secreted proteins and virulence of the entomopathogenic fungus Beauveria bassiana. J Invertebr Pathol 105:270-278

Roberts DW (1981) Toxins of entomopathogenic fungi. In: Burges HD (ed) Microbial control of pests and plant disease 1970-1980. Academic Press, London, pp 441-463

Sahayaraj K, Tomson M (2010) Impact of two pathogenic fungal crude metabolites on mortality, biology and enzymes of Dysdercus cingulatus (Fab.) (Hemiptera: Pyrrhocoridae). J Biopest 3:163-167

Sintim HO, Tashiro T, Motoyama N (2009) Response of the cutworm Spodoptera litura to sesame leaves or crude extracts in diet. J Insect Sci 9:52

Slansky F, Scriber JM (1982) Selected bibliography and summary of quantitative food utilization by immature insects. Bull Entomol Soc Am 28:43-55

Suganya T, Selvanarayanan V (2010) In vitro study on the effect of bhendi varieties on the infectivity of Beauveria bassiana (Bals.) Vuill to Spodoptera litura Fab. J Biopest 3:369-372

Tefera T, Pringle KL (2003) Effect of exposure method to Beauveria bassiana and conidia concentration on mortality, mycosis, and sporulation in cadavers of Chilo partellus (Lepidoptera: Pyralidae). J Invertebr Pathol 84:90-95

Thomsen L, Eilenberg J (2000) Entomophthora muscae resting spore formation in vivo in the host Delia radicum. J Invertebr Pathol 76:127-130

Vey A, Hoagland R, Butt TM (2001) Toxic metabolites of fungal biocontrol agents. In: Butt TM, Jackson CW, Magan N (eds) Fungi as biocontrol agents: progress, problems and Potential. CAB International, Wallingford, pp 311-346

Waldbauer GP (1968) The consumption and utilization of food by insects. Adv Insect Physiol 5:229-288

Wang L, Huang J, You M, Guan X, Liu B (2007) Toxicity and feeding deterrence of crude toxin extracts of Lecanicillium (Verticillium) lecanii (Hyphomycetes) against sweet potato whitefly, Bemisia tabaci (Homoptera: Aleyrodidae). Pest Manage Sci 63:381-387 